This item was submitted to Loughborough's Research Repository by the author.

Items in Figshare are protected by copyright, with all rights reserved, unless otherwise indicated.

\title{
HADRIAN: a virtual approach to design for all
}

PLEASE CITE THE PUBLISHED VERSION

http://dx.doi.org/10.1080/09544820903317019

PUBLISHER

(c) Taylor and Francis

VERSION

AM (Accepted Manuscript)

LICENCE

CC BY-NC-ND 4.0

REPOSITORY RECORD

Marshall, Russell, Keith Case, J. Mark Porter, Steve Summerskill, Diane E. Gyi, Peter M. Davis, and Ruth Sims. 2019. "HADRIAN: A Virtual Approach to Design for All". figshare. https://hdl.handle.net/2134/10645. 
This item was submitted to Loughborough's Institutional Repository (https://dspace.lboro.ac.uk/) by the author and is made available under the following Creative Commons Licence conditions.

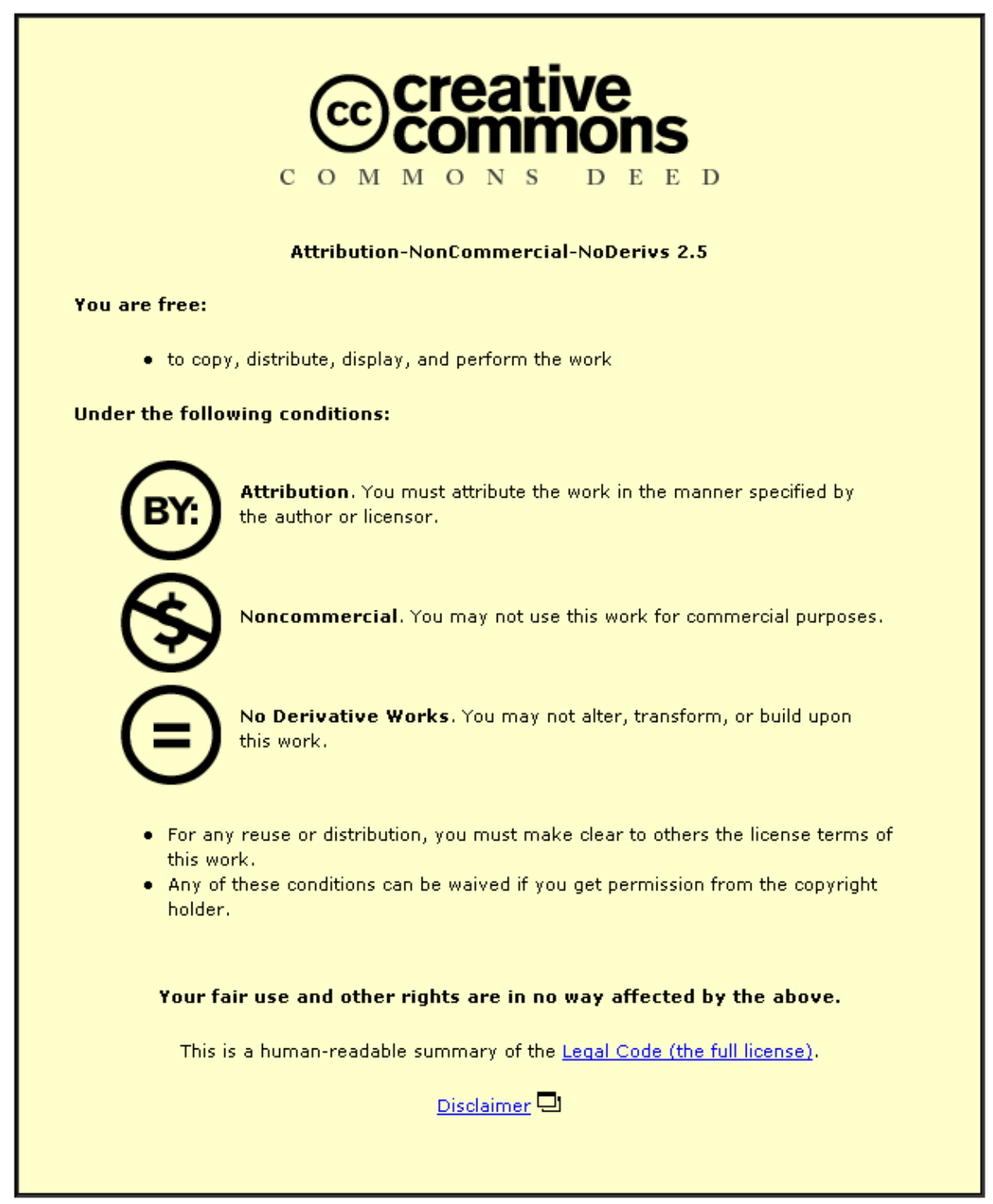

For the full text of this licence, please go to: http://creativecommons.org/licenses/by-nc-nd/2.5/ 
Journal of Engineering Design Special Issue on Inclusive Design

Vol. 21, No. 2-3, April-June 2010, 253-273

\title{
RESEARCH ARTICLE
}

\section{HADRIAN: a virtual approach to design for all}

\author{
R. Marshall ${ }^{a^{*}}$, K. Case ${ }^{b}$, J.M. Porter ${ }^{a}$, S.J. Summerskilla, D.E. Gyi ${ }^{\mathrm{c}}$, R.E. Sims ${ }^{\mathrm{a}}$ and P. Davis ${ }^{\mathrm{a}}$ \\ ${ }^{a}$ Department of Design and Technology, ${ }^{\mathrm{b}}$ Department of Mechanical and Manufacturing Engineering, ${ }^{\mathrm{c}}$ Department of \\ Human Sciences, Loughborough University, Loughborough, UK
}

This paper describes research into the area of 'design for all'. The research addresses two common needs for designers working towards developing inclusive products and environments, namely data on users that is accessible, valid, and applicable and a means of utilising the data to assess the accessibility of designs during the early stages of development. The approach taken is through the development of a combined database and inclusive human modelling tool called HADRIAN. Data were collected on 100 people the majority of whom are older or have some form of impairment. These individuals provide a browsable resource spanning size, shape, capability, preferences and experiences with a range of daily activities and transport related tasks. This is partnered with the development of a simple, CAD based task analysis system. Tasks are carried out by the virtual individuals in the database and accessibility issues reported, allowing excluded people to be investigated in order to understand the problems experienced and solutions identified. HADRIAN is also being expanded to include a more accessible journey planner that provides accessibility information to both end users and transport professionals. Together HADRIAN allows more informed choices to be made either in travelling, or in the designing of products and environments.

Keywords: inclusive design, ergonomics, human modelling, product design

\footnotetext{
* Corresponding author. Email: r.marshall@lboro.ac.uk
} 


\section{Introduction}

There is significant evidence that products, services and environments should be designed for all, should be inclusive, and should avoid discriminating or disadvantaging users based on their size, shape, age, abilities, needs, or aspirations (Coleman et al 2003). It could be argued that 'good design' will meet this standard, addressing the complete scope of customer, and other stakeholder, requirements. However, the wealth of published material and significant research base around inclusive design indicates that 'good design' is perhaps not as common as it might be. The drivers for inclusive design are clear, the ageing population is well documented and provides a significant financial case for design outcomes to meet the needs of older people (Keates and Clarkson 2003). Legislation has been implemented to prevent discrimination (DDA 2005). There is also a strong moral case that design should not be embodying a philosophy that prevents certain people from using, and enjoying the products, services and environments that it produces. The strength of these drivers would suggest that exclusive design is perhaps not just down to belligerent (younger, able bodied) designers deliberately designing for themselves, or their colleagues, but that there is a more fundamental issue. Indeed, recent research publications, conferences, networks, workshops and other such events have highlighted that designers are increasingly 'on board' with inclusive design. They increasingly recognise the drivers for inclusive design and the potential in achieving a solution that not just meets the basic needs of all users but surpasses them and makes the design a pleasurable experience for all. Thus, if the willingness for inclusive design is common within the design community, and that the recognition of the need is common within the design community, what then leads to designs still being produced that incorporate short-sighted and exclusive decision making?

The complexity of design should not be underestimated and often designers are managing a complex

array of stakeholder requirements. Some requirements may be conflicting and demand different directions for the design, for example a business's desire for standardisation and rationalisation vs. the customers desire for variety and customisation or personalisation. In these cases the approach is to provide a means to support the design process and the designer in understanding the issues and in working towards the appropriate solution. Research at Loughborough University has taken this approach with two computer based tools at its core. SAMMIE (System for Aiding Man Machine Interaction Evaluation) and HADRIAN (Human Anthropometric Data Requirements Investigation and ANalysis) have both been developed to support designers and ergonomists in developing products that better meet the needs of users. Together the tools support 'playing' with ideas at an early stage in the design process and provide feedback as to the impact of those ideas on users. In principle, the tools take the model of fitting trials, or user trials that are performed with real people and real products and move that into a virtual world where the costs and complexities of the real world are avoided and yet some of the valuable feedback is available in a much more timely manner.

We believe that there is a need for a new approach in order to effectively support designers when attempting to 'design for all' that must take into account a number of important issues:

- Tools are often data driven. If the data is unavailable, inaccurate, misleading, unapplicable or just difficult to apply then often the tool is of limited value.

- Even with accurate, applicable data, tools provide an additional layer of activity and often require some expertise.

- If a design team lacks the expertise in a particular discipline tools may be used to mitigate against this. Assuming tools are easy to use it can often be the case that the tool is used without a full understanding of the results or advice provided by the tool. Indeed tools can often be used to justify a poor decision as easily as a good one. 
- Tools are rarely good at addressing the softer, cognitive or emotional issues within design, for example: how products' elicit pleasure, how individuals behave when asked to use a product, or the cognitive load placed upon a user by a particular design. Even if the tool manages this element of design well, it is not straightforward what needs to be done.

This paper will describe our research that since 1999 has led to the formation of our design ergonomics approach to inclusive design and the development of HADRIAN. In addition, the paper will outline the early stages of validation taking place that will assess the current state of HADRIAN and also act as a driver for future refinements. Finally the paper will briefly introduce ongoing research into two sister tools for HADRIAN that go beyond the assessment of discrete products or facilities and address a whole system in the form of transport and the inclusiveness of a whole journey.

\section{Designers' needs when attempting to design for all}

Ergonomics plays a significant role in design activity and is the source of data on the size, shape and capability of people. An appreciation of these data is fundamental if a design is to be suitable to address the variations of people within a population. However, even in so-called population databases there are limitations placed upon the scope of the data. One of the most common anthropometric databases is Adultdata, published by the Department of Trade and Industry (1998). Adultdata is actually a compendium of data from other sources drawn together in one useful volume (including Pheasant 1996 and Peoplesize 1998 amongst others). The data span 266 physical body measurements for multiple nationalities. However, not all measures are available for all nationalities, so for example, it is possible to obtain a stature measurement for the German population but there is no German data for arm length. In addition most of the data was collected many years ago. Adultdata was published in 1998, but the sources of data within it range from 1969 to 1998. The data have been statistically treated through ratio scaling to factor in increases in stature and weight in many of the world's populations over this time period, however much of the data is, at best, 10 years old. Investigating further highlights other issues such as the fact that the Chinese data was actually collected from Singapore and Hong Kong. Other sources are taken from particular occupations such as Swedish and Polish workers, and French car drivers. Some of the sample sizes are relatively modest (1051 people) to be representative of a whole nationality.

Other databases such as SizeUK (Treleaven 2007; SizeUK 2008) and CAESAR (Robinette et al 1999; CAESAR 2008) provide a very large array of measurements taken from many thousands of people. Their age, number of people and sampling strategies make them much more representative of their respective populations. However, they are relatively expensive and often beyond the reach of many designers.

Further limitations, particularly relevant to designers wishing to design for all, relate to the age range of the samples in the databases. Adultdata and CAESAR do not have data on people who are older than 65 years although SizeUK does have people up to the age of 91 and Older Adultdata (one of the Adultdata series together with Childdata) have data from people over 90 for some nationalities. This is a common limitation for anthropometric databases and thus do not factor in changes to body size and shape as people age. The lack of data from people with impairments is also a fundamental issue. The effects of common impairments are rarely reflected in anthropometric data and when they are they tend to be from samples of limited size or with other limiting factors (Paquet and Feathers 2004; Das and Kozey 1999; Hobson and Molenbroek 1990; Goswami, et al 1987).

Whilst all of the limitations above are often explicitly stated in the databases, what is not clear is the impact these limitations have if the data are used to inform a design. Issues associated with the age of the data may be relatively minor, issues to do with the age of the people in the data are more significant, issues from 
only having data on able bodied people when wishing to design to include all people, including those with disabilities, is fundamental.

Assuming data to be available another significant issue is how designers and ergonomists might apply the data to common design problems. Anthropometric data is commonly presented as a percentile value. Percentiles are merely numerical values that represent a point on a scale from $>0$ to $<100$ that is associated with some measurement. These values are used to indicate a percentage of the population that will have measures less than the indicated point on the scale. Thus, $5^{\text {th }}$ percentile (\%ile) for stature means that $5 \%$ of the population will have a stature that is shorter than this measurement. $95^{\text {th }} \%$ ile arm length means that $95 \%$ of the population will have arms that are shorter than this measurement. Typically these data will also be related to a gender and a particular nationality for example, $5^{\text {th }} \%$ ile UK female stature is $\mathrm{X}$ mm. This method of presenting anthropometry seems straightforward but is notoriously confusing and has a number of issues when it is used for design (Porter et al 2004):

- Most anthropometric databases only provide data on $5^{\text {th }}, 50^{\text {th }}$ and $95^{\text {th }} \%$ ile measurements. This encourages designers and indeed even supports designers excluding the top and bottom 5\% of the population. Even though other percentiles can often be calculated this is far from explicit and not clear for a non-expert user.

- The issue of multivariate accommodation is rarely addressed. Most design problems are multivariate and yet percentiles are univariate. The process of breaking down people into individual measures and statistically treating them has removed any link from the people they used to represent if we wish to consider more than one measure at a time. Whilst strong correlation does exist between certain measures many measures have very poor correlation between them. The implication being that a person with a $5^{\text {th }}$ $\%$ ile stature probably will not have $5^{\text {th }} \%$ ile weight, sitting height, shoulder breadth and so on. Due to poor correlation the $5 \%$ excluded due to their stature may be different to the $5 \%$ excluded due to their sitting height. The more variables the greater the level of exclusion. Roebuck, Kroemer and Thomson (1975) showed that designing from $5^{\text {th }}$ to $95^{\text {th }}$ for a large number of dimensions actually designed out nearly $50 \%$ of the intended population.

- Data are often presented as faceless tables of numerical values. Designers need to have empathy with those they are designing for. Designing out $5 \%$ of the population is difficult to appreciate when the population is probably ill defined and the total number of people is not known.

The final concern is that data are largely unspecific to a particular task or environment. Yet the design they are being applied to is likely to be very specific. One simple illustration of this is that data are often collected without clothing yet there are few design situations where we would need to know the dimensions of the naked population. Factoring in standard clothing allowances makes the task much more complex and requires a high level of experience and expertise, to allow for heavy, bulky and restrictive safety equipment is more complex again. In an inclusive design context the task and environment may be relatively common, cooking a meal in a kitchen or getting a ticket from a ticket machine on a train platform. However, older and disabled people often employ coping strategies that mitigate against any impairment they may have. These coping strategies are rarely documented and add yet another layer of complexity to the designer wishing to design for all.

\section{The beginnings of our approach}

Our current approach to inclusive design began, supported by funding from the Engineering and Physical Sciences Research Council (EPSRC), as part of the Extending QUAlity Life (EQUAL) initiative and, in particular, the Design for All strand of the programme. An early survey of 50 designers aimed to identify the 
current situation in designing when taking into account the needs of older and disabled people (Gyi et al 2000). The results highlighted a number of issues including confirmation that available data tends to be 'patchy' and rarely in sufficient detail to enable professionals engaged in product design to make more informed decisions. In addition, existing data tools are not in a format or language that designers can access and relate to easily. Finally it was noted that the majority of designers used at least one computer aided design package and most of the designers used more than one. These findings have also been identified amongst a broader range of concerns for businesses in a more recent study by Goodman et al (2006). From this we identified that there is a clear need to provide ergonomics data in a highly visual form and to integrate Design for All philosophy into existing good practice, such as the use of CAD and other computer based design tools such as SAMMIE (Porter et al 2004).

SAMMIE is a computer aided human modelling system, similar to other systems such as JACK, RAMSIS and SAFEWORK (Raschke 2004; Seidl 2004; Morrissey 2004) that allow ergonomics issues to be explored in a CAD environment whilst ideas are being investigated and decisions made on design directions (Figure 1). The benefits of being able to explore issues such as fit, posture, reach and vision at an early stage of the design are invaluable in achieving products that fully accommodate users. Clearly real user trials can be conducted that involve real people and a mock-up or prototype of the design but these cannot, by their very nature, be conducted at an early stage. They are typically expensive in both time and money and are not really suitable for rapid iteration and exploring concepts. Performing this analysis in the CAD environment has become a popular technique widely used in many industries (SAMMIE CAD 2008).

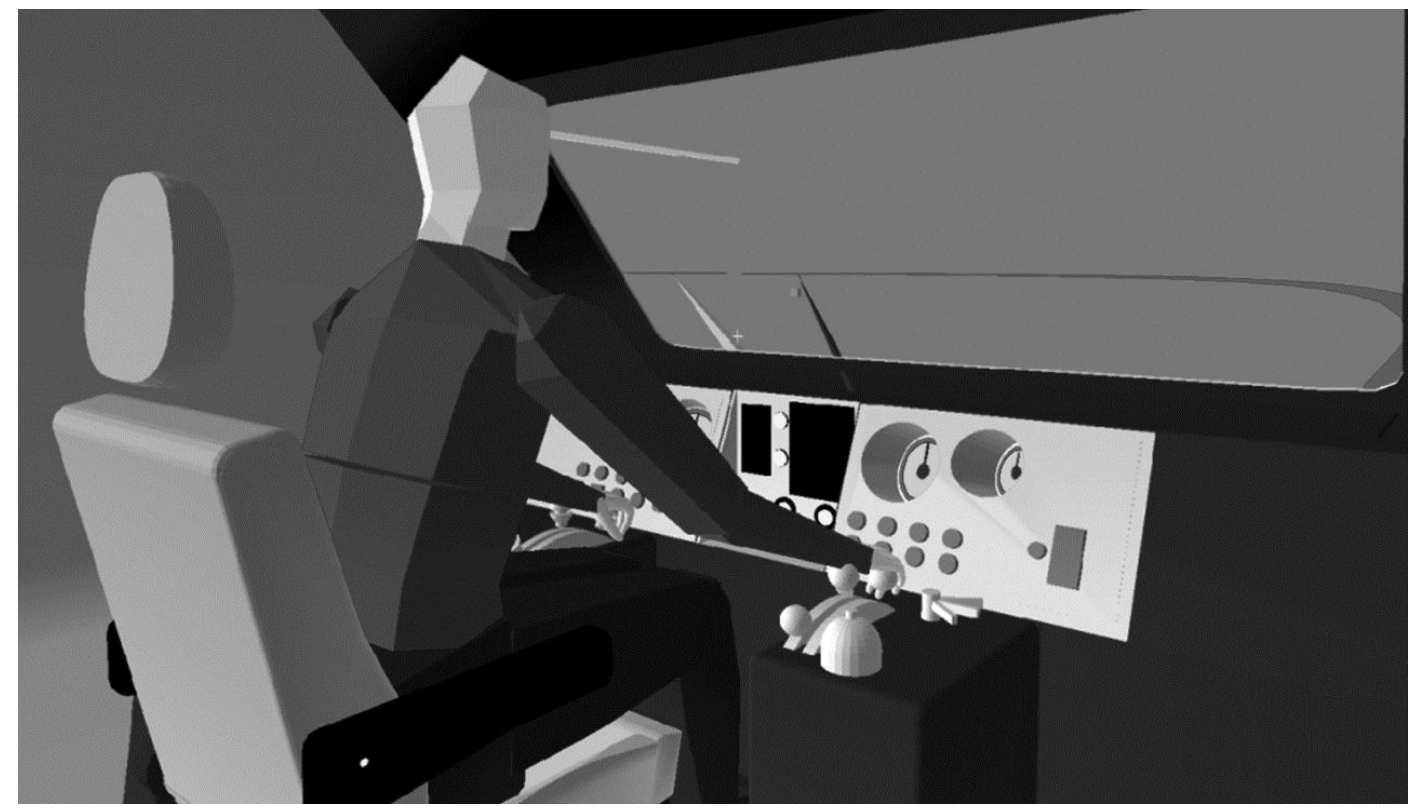

Figure 1. The human modelling system SAMMIE being used in the evaluation of a train cab design for the Rail Safety and Standards Board (RSSB).

As we have seen there are many issues when trying to apply ergonomics data to design, the same is true of ergonomics tools such as human modelling systems. These tools are driven by the same anthropometric sources already discussed and also suffer from the same issues. In addition, the successful use of such tools is often coloured or constrained by the need for 'expert' users. It is still the case that many design companies and manufacturers do not have qualified and experienced in-house ergonomists or human factors specialists. Many companies make internal appointments to such a role and, consequently, the ergonomics issues are often dealt with by a non-specialist without the formal support that may be required in terms of education, 
facilities and research networks. For ergonomists to truly support widespread design practice, we need to develop and communicate information and methods that meet the needs of designers themselves (Porter and Porter 1999). The literature provides many examples of ergonomics information being inappropriately used by designers, if it is used at all (Pheasant 1996; Hasdogen 1995). Much of the published information is summarised in the form of guidelines for designers but these are, by their very nature, more of a prescriptive evaluative tool than a predictive tool for supporting the development of creative and innovative design solutions.

\section{HADRIAN}

In response to the issues discussed earlier it was decided to develop an inclusive design tool. This tool is called HADRIAN and works together with SAMMIE to target the first two bullet points outlined in the introduction, namely: the provision of relevant, accessible and holistic information on people of a broad range of size, shape, and ability and a means of utilising the available information to assess the inclusiveness of a proposed design.

\section{A database of highly relevant, applicable data}

The HADRIAN database consists of physical and behavioural data on 100 individuals covering a broad range of ages and abilities. The age of people in the database ranges from 18 to 89 years with 46 people who are over 60. Fifty-nine people have some form of impairment including: limb loss, cerebral palsy, epilepsy, head injuries, non specific knee problems, multiple sclerosis, arthritis, vision and hearing impairments, heart problems, paraplegia, Parkinson's disease, stroke, and dyslexia, amongst others. Of the 43 able bodied people 20 were aged over 60 and had undiagnosed or minor impairments associated with being older.

The sample is clearly not representative of the more general population. This was a deliberate decision to skew the data towards the older and disabled. However, the sample has been carefully selected to cover as broad a range as possible for every measure recorded. Thus for example, the database covers from $1^{\text {st }}$ to $99^{\text {th }} \%$ ile on most anthropometric measures with at least one person in each decile, the data spans from 1 to 9 on the OPCS severity scores (Martin et al 1994), and there are over 20 recognised impairments represented in the database. In addition, the collection of data from 100 individuals was determined by the need to cover this breadth but also remain a pragmatic target for the project given the significant efforts the data collection requires.

A key feature of the database is how the data are presented (Figure 2). To address concerns with designers being presented with faceless numbers, with the lack of visualisation in current tools, and in the complexities of multivariate accommodation, the database is effectively a catalogue of individuals. Data are not broken down into categories of individual measures but are instead maintained as a set associated with a single person. Thus the user can browse through the people in the database see a picture of that individual and explore the data about that person. This approach fosters empathy between the designer and the people who they are designing for, and attempts to minimise the dehumanising effects of percentiles and of the virtual environment in which the design is being created.

A pilot trial was conducted to identify the number of anthropometric and mobility measures to record, issues with data collection methods and to explore novel methods such as motion capture (Marshall et al 2002). In addition the pilot ensured that the timescales for data collection were appropriate to avoid fatigue and that the subjects were comfortable with the data collection process. Final data collection (Table 1 and Gyi et al 2004) captured 28 anthropometric body measures, 18 joint angle ranges of motion, reach range in the form of a reach envelope or volume, grip strength, manual dexterity and a range of more general information 
on age, occupation, nationality, work history and so on. This data was also accompanied by two photographs taken from the front and side of the individual.

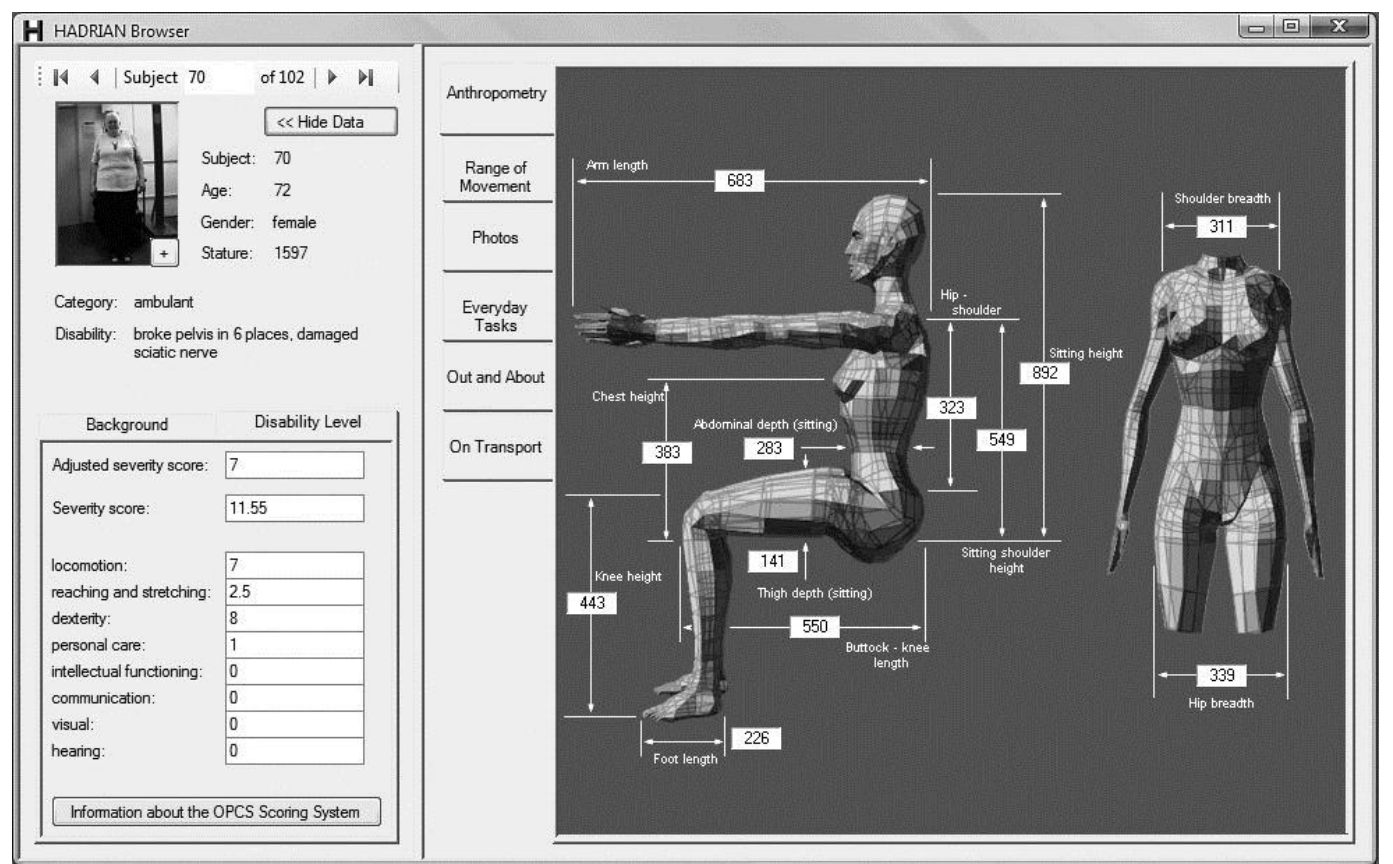

Figure 2. Screen shot of the prototype HADRIAN database - showing anthropometric data for an individual.

To address the need for more applicable data is was decided that the database should not just be an anthropometric data source but should also capture ability related to design applicable tasks. A second survey, this time of user needs, conducted with 50 older and disabled people highlighted relevant activities and tasks that could be a focus for investigation (Oliver et al 2001). The two primary responses were: being able to prepare meals for friends and family; and being able to use local transport. This lead to a focus on kitchen based tasks and a range of more generic seating scenarios, ranging from bus to toilet seating, for initial data collection. Taking a pragmatic approach the data collection focused on tasks that were sufficiently specific to be relevant to design needs, yet generically applicable so that we were not designing a kitchen design tool, or creating a system that required data on every possible task situation in order to be useful. Where possible the data collected reflects real-world application. Thus, comfort maximums were recorded to reflect what the subject would be likely to do in their own home where absolute maximums would not normally be used. In addition, tasks that represented hot loads such as lifting items into and out of the oven were performed using oven gloves to represent their affects on capability and behaviour.

All task activity was recorded from two positions via digital video camera and subsequently used to provide video clips of the task being performed (Figure 3). Task data stored within the database includes a success or a failure for each task element. In addition, the data also records how a task was performed in terms of task behaviour. Table 1 gives an idea of the scope of the data captured within the database. 
Table 1. Summary of data in HADRIAN database.

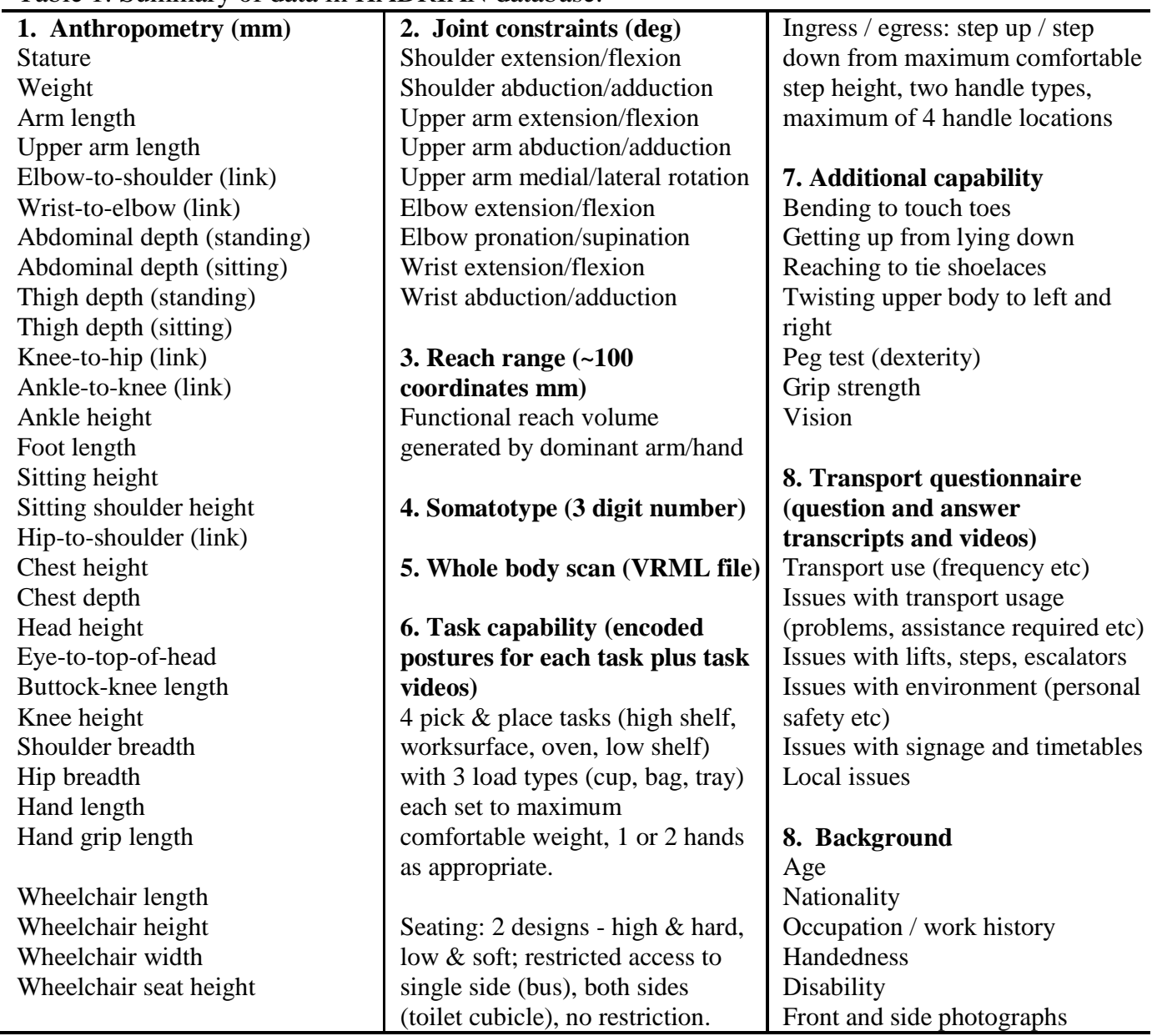

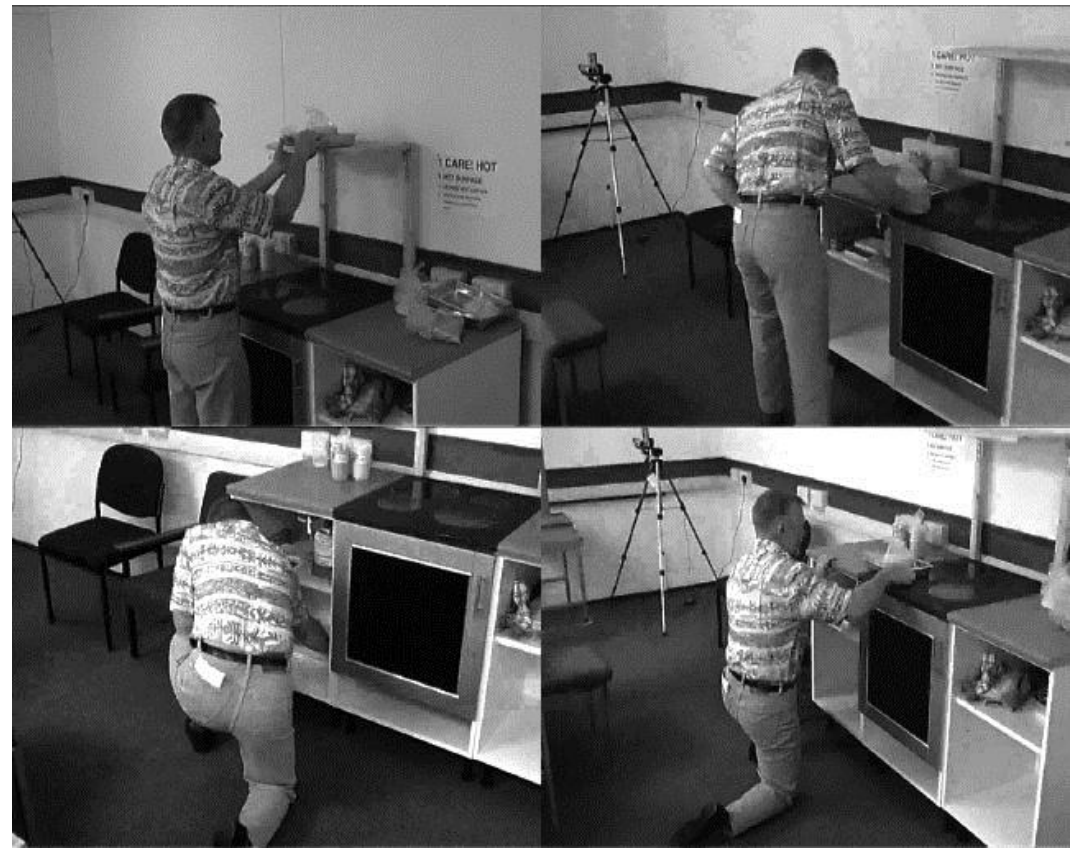

Figure 3. Individuals performed a variety of kitchen based tasks from which capability and behaviour were recorded. 


\section{An inclusive design analysis system}

Capturing behaviour was a key part towards meeting the second target for the HADRIAN system, namely a means of utilising the data to assess the inclusiveness of a proposed design.

As we have discussed, human modelling systems provide the ability to analyse early design ideas within a CAD system. The predictive results from such a process provide a much stronger emphasis on the need for sound ergonomic solutions during the design process and enable the designer to be more proactive in achieving inclusive designs. Thus it was envisaged that we could combine expertise in human modelling through the SAMMIE system with a new tool that aimed to support designers in the use of human modelling. This new tool could then address the issues with appropriate data and how the data may be used when access to ergonomics or human factors expertise may be limited.

The approach taken in development of the analysis capabilities of HADRIAN focuses on an integrated approach to support the designer in defining a task description associated with using their design, subsequent analysis of the task performed with the design, and final result reporting and analysis feedback (Marshall et al 2002). This approach then aids the designer in the evaluation of a specific design, establishing a form of semi-automated virtual fitting trial. This fitting trial can then be performed many times using the individuals in the database as human models.

The analysis system was designed to facilitate a means of describing how a product would be used. 'Product' is taken in its broadest context and may include any object that requires physical interaction. The system allows a complete task such as "withdraw cash from the ATM" to be broken down into recognisable elements such as "insert card" or rather its interpretation as "reach to card slot". Whilst a task is essentially a dynamic process the approach taken is to determine key-frames, or essentially static snapshots, of the task on which to base the analysis. SAMMIE provides the functionality to model the elements of these static snapshots, namely: a posture for the human model, a target object, and an environment. The modelling then responds to each individual task element in a chain, performing physical interactions, and assessing the success of each element towards completing the task.

In an attempt to make the analysis as realistic as possible the system uses the task behaviour recorded from the individuals in the database. This behaviour is encoded into postures that the individuals adopt for a generic task. This postural behaviour is then replicated when an individual in the database is asked to perform a task of a similar nature. Thus participant behaviour when reaching to the high shelf in the kitchen tasks is taken as a generic approach to all tasks that require a reach to a point above the shoulder for that individual. The actual process of performing the task is embodied within the posture and positioning of the human relative to the product. SAMMIE already contains some tools to aid in the process of determining posture for task related elements such as reach in addition to a number of standard postures. These standard tools are combined with the behavioural data to form an underlying task model that the system will apply in order to try to perform the task as described by the designer.

The actual process of describing a task element involves a process of defining interaction points and describing those through the selection of a command and a target together with some optional parameters (Figure 4). If we were to continue with the ATM example above, the first command may be 'look' to represent the need to read any on screen instructions at the start of the interaction. The command then needs a target that will be represented within the model to be analysed, in this case 'screen'. This target will be the focus of the task element and form a verb + noun pairing such as Look at Screen, Reach to Card Slot. The task definition is then completed through the specification of task parameters. This may include an acceptable viewing distance, a particular grip type to adopt, or what limb a reach should be performed with. In the ATM example illustrated the reach task is given a specific grip parameter to represent the need to insert the card with a pinch grip (thumbtip grip) as opposed to being able to reach with a fingertip which would be insufficient to allow insertion of the card. Which arm to use is left as 'not specified' to allow the system to 
decide the most appropriate arm based on the capabilities of the individual performing the task and the specifics of the evaluation at that point (i.e. which arm is nearest the target).

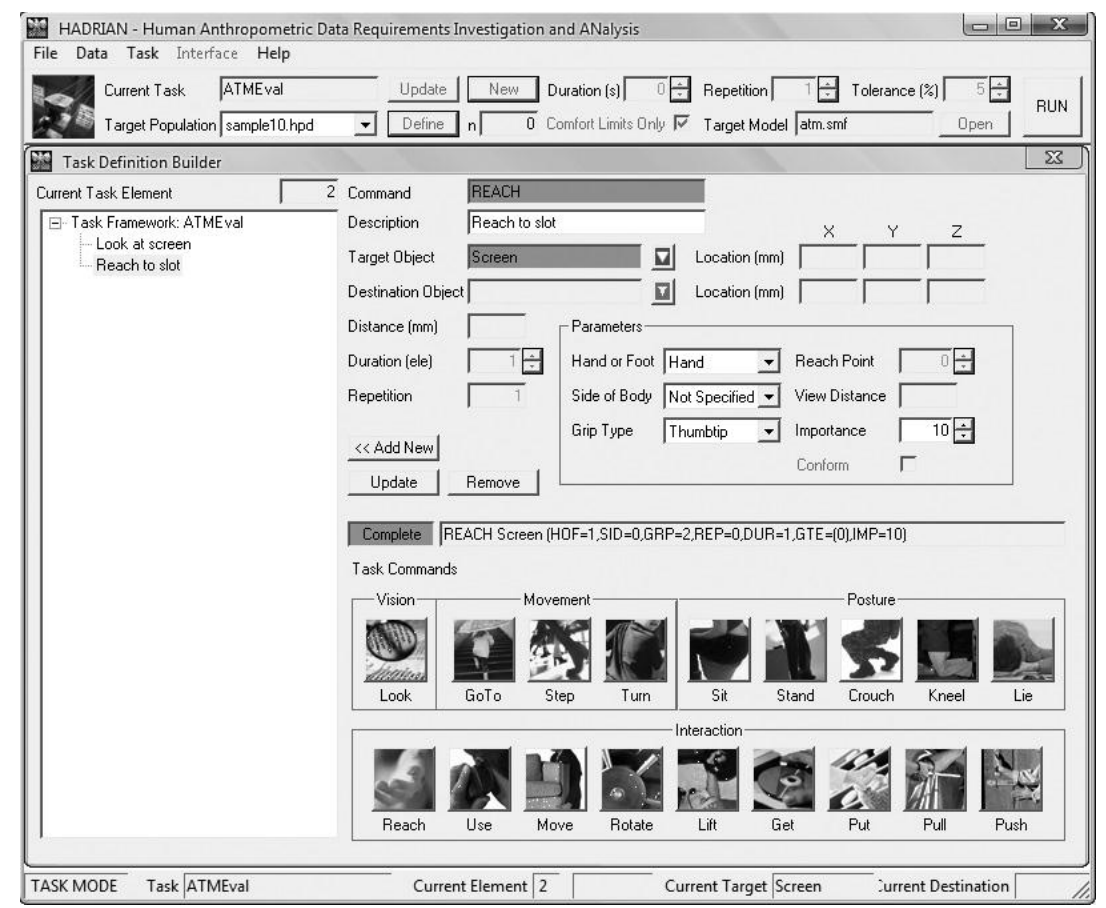

Figure 4. Screen shot of the prototype HADRIAN task analysis system, showing the building of a task definition.

HADRIAN has been designed to ensure that the designer focuses on 'what' is to be achieved in the analysis. Whilst some processing is inevitable to break down an overall task into elements the designer does not need to make decisions about 'how' the task is performed. Instead HADRIAN synthesises how the task is performed through the use of a task framework. This automation of the analysis allows the designer to gain access to the feedback available from a human modelling tool without the necessary human modelling expertise.

The task framework addresses two core elements of how an analysis is performed. The first is what manipulation is performed to the human model in response to the task element. The second is how task elements interact such that any particular task element posture is optimised relative to the previous and future task elements.

Depending on the number of parameters specified in the task element description the task framework firstly makes a decision as to what part of the body is primarily affected by the task. Thus a reach task may have the associated parameter of Reach with Hands and so the arm is the starting point for the analysis. However there is no requirement for the user to specify which hand (though it can be specified if desired). Here the system begins to explore what it knows about the individual currently performing the task from the data in the database and also the range of task elements. Whilst a full treatment of the analysis model is beyond the scope of this paper, various factors are taken into consideration including dominant hand of the individual, the current orientation of the individual, the nearest hand to the target, any impairments to the non dominant arm/ hand, the details of the next task element, and so on. For example, an individual who is right handed but with no impairment to their left arm/hand, and who is oriented such that the reach point is much closer to their left hand may attempt to perform the reach task left handed. Figure 5 illustrates orientation differences for wheelchair users. These differences are attributable to the task setup and the behavioural coding of the individuals. Orientation is a particular concern for wheelchair users due to the obstructing nature of the chair itself. 


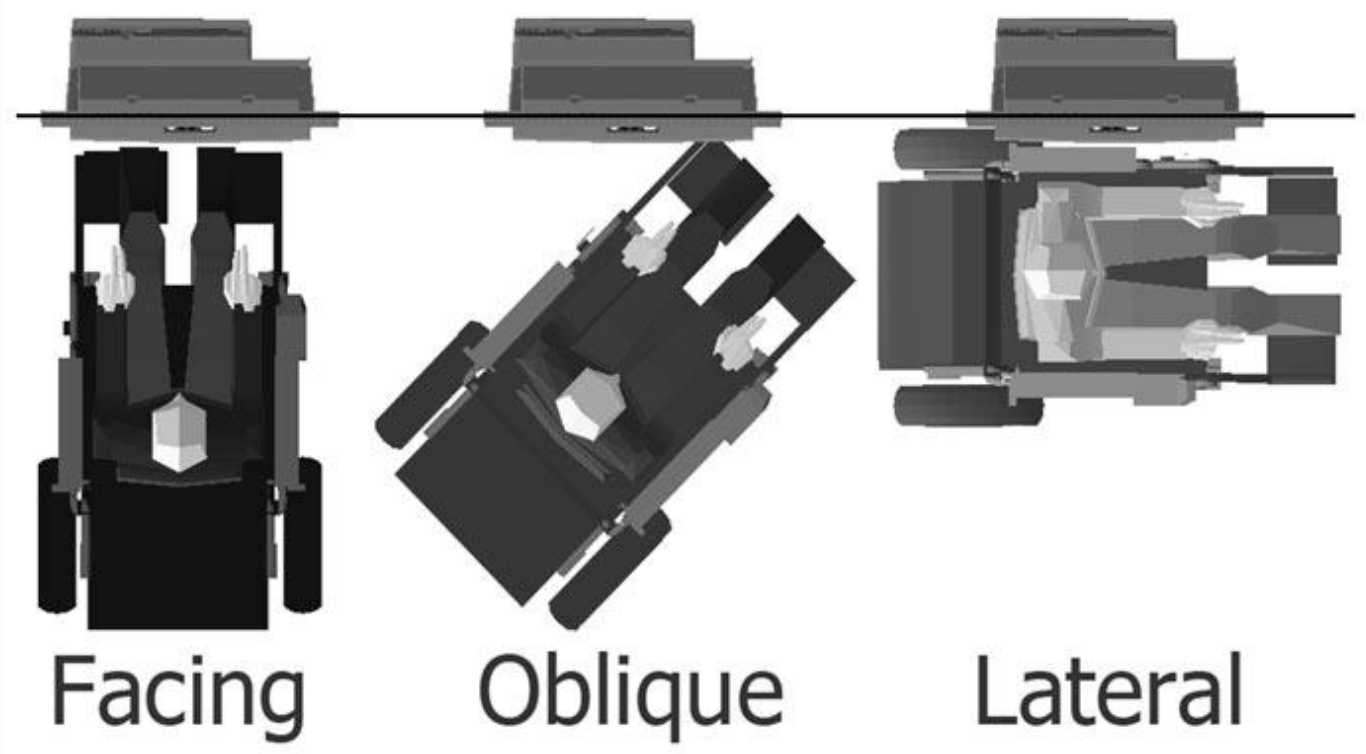

Figure 5. Orientation differences for a wheelchair user during a task analysis within HADRIAN.

The posture adopted by the reach will be determined by the distance the target is away and the behavioural coding associated with this individual. Figure 6 illustrates the observed behaviour of two people from the database and that behaviour being replicated posturally for a similar task in HADRIAN. Continuing with the example, if the target reach point is close to the ground and the individual was observed to always kneel down when reaching to low points the human model will adopt a kneeling posture optimised such that the reach point is within reach, if possible. Whilst this outlines the initial approach, if a failure occurs for any task element further possibilities may be explored and initially rejected options tried.

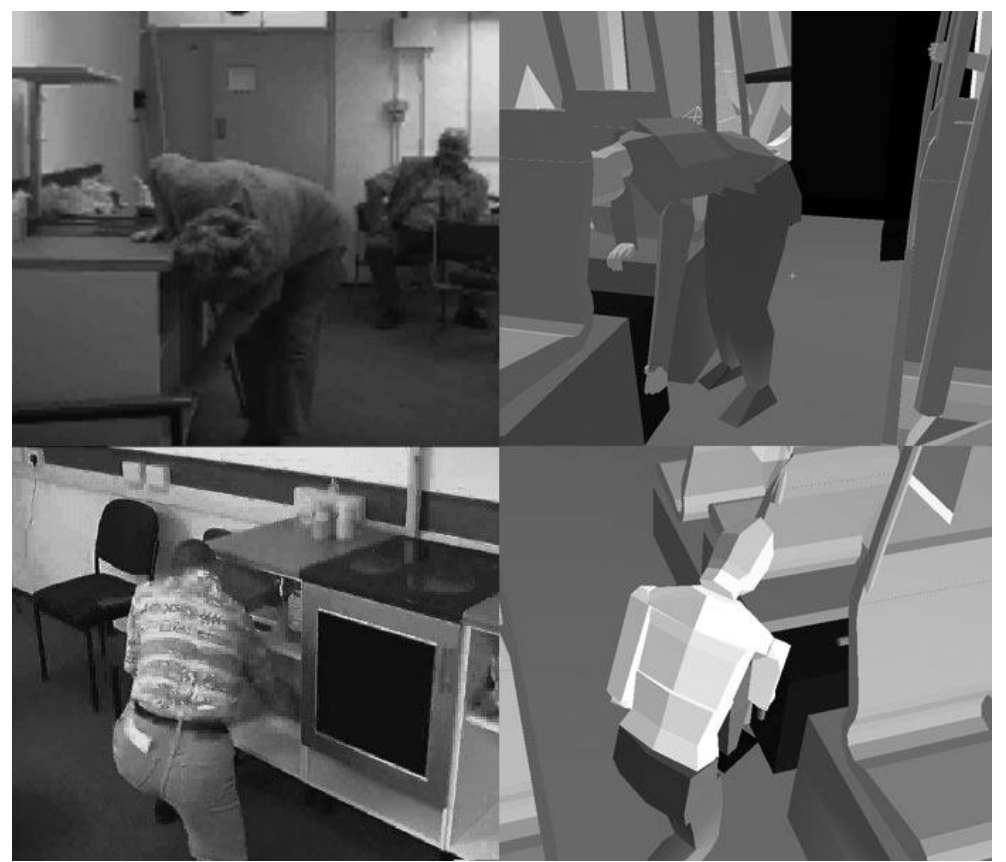

Figure 6. Postures adopted within a task analysis influenced by the behavioural coding recorded for individuals in the database. 
The influences of past and future task elements on the current task element are also taken into account. The process outlined above may be influenced by adjustments to the orientation and location of the human model, and its starting posture. In addition, the system will factor in task elements that may be associated with one another spatially. These associations are mapped over the task area and weighted based on the number of interactions within a given area. Areas with concentrations of task elements may be given priority when locating, orienting or posturing the human model.

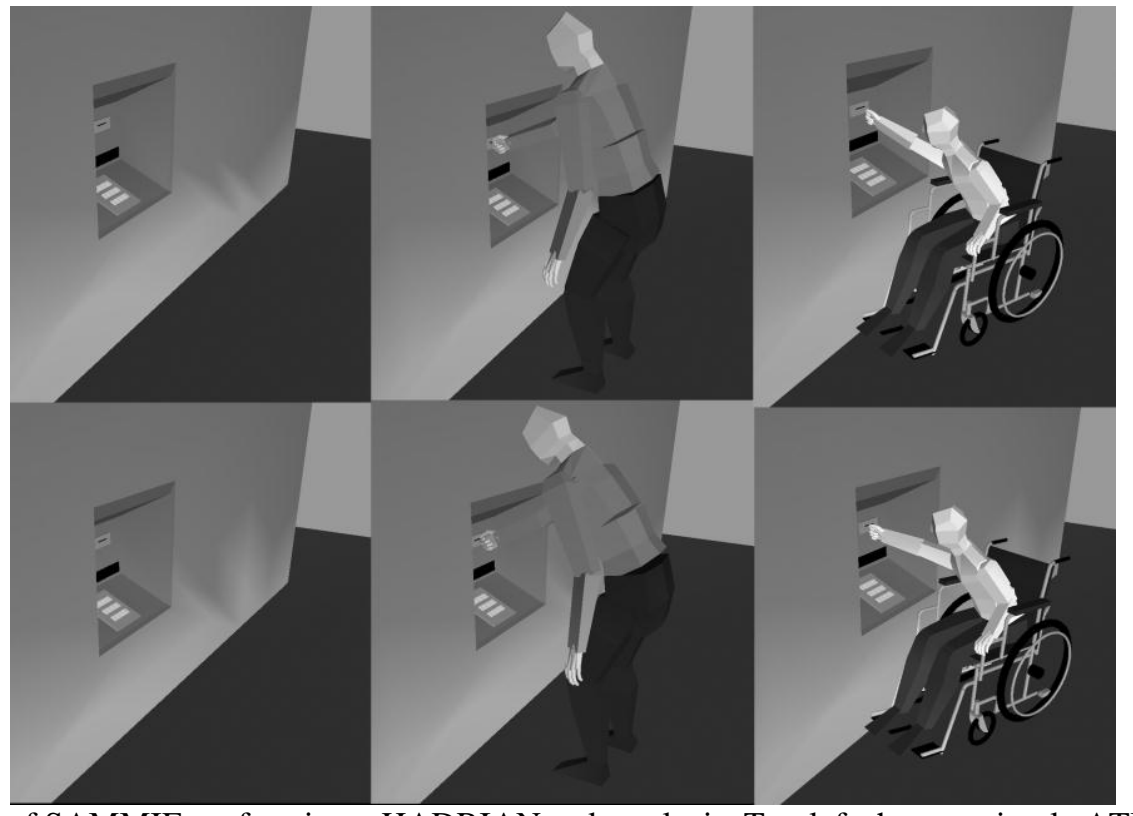

Figure 7. Screen shots of SAMMIE performing a HADRIAN task analysis. Top left shows a simple ATM model. Top middle shows a tall individual in the database successfully performing a reach task to the card slot. Top right shows a wheelchair user from the database failing to reach the card slot. Bottom left shows the same ATM model with a quick change of dropping the whole ATM by $100 \mathrm{~mm}$. Bottom middle shows the tall individual still able to reach the card slot. Bottom right shows the wheelchair user is now capable of reaching the card slot.

Irrespective of the underlying complexity of the process, the designer sees individuals in the database attempting to perform the task as defined. Each individual will have their own size, shape, capability and behaviour represented in the human model. The individuals will all perform the task slightly differently based on the process outlined above. Figure 7 illustrates the evaluation of a simple ATM concept and shows two individuals (top row of images) attempting the reach task element (Reach to Slot). The tall individual in the middle image is successful, but the wheelchair user cannot reach. The outcome of the analysis is then reported to the designer in terms of a percentage excluded (Figure 8). The percentage is based upon those individuals in the database and so if 10 of the 100 people fail to achieve the task then $10 \%$ are reported excluded. The designer can then explore those who failed, identify exactly which individuals experienced problems, with what part of the task and why. The designer may now explore the affects of changes to the design or even the task. As both are effectively independent, changes can be made to the design and the task run again without having to redefine it. Because the process is occurring during an early stage of the design, possibilities can be rapidly explored and an optimum quickly identified. Figure 7 also illustrates a quick change to the ATM model after the initial feedback (bottom row of images) where the ATM has been dropped by $100 \mathrm{~mm}$ in height and this results in both individuals being able to complete the task. Whilst the individuals are successful in achieving the task the designer can also make an assessment of the acceptability of the postures adopted, clearly the tall individual is having to bend quite significantly to reach and see. Whilst 
HADRIAN is not an intelligent design system, it can highlight the key variables that are involved in the failure and direct the designer's attention to the fundamental reasons for the problem.

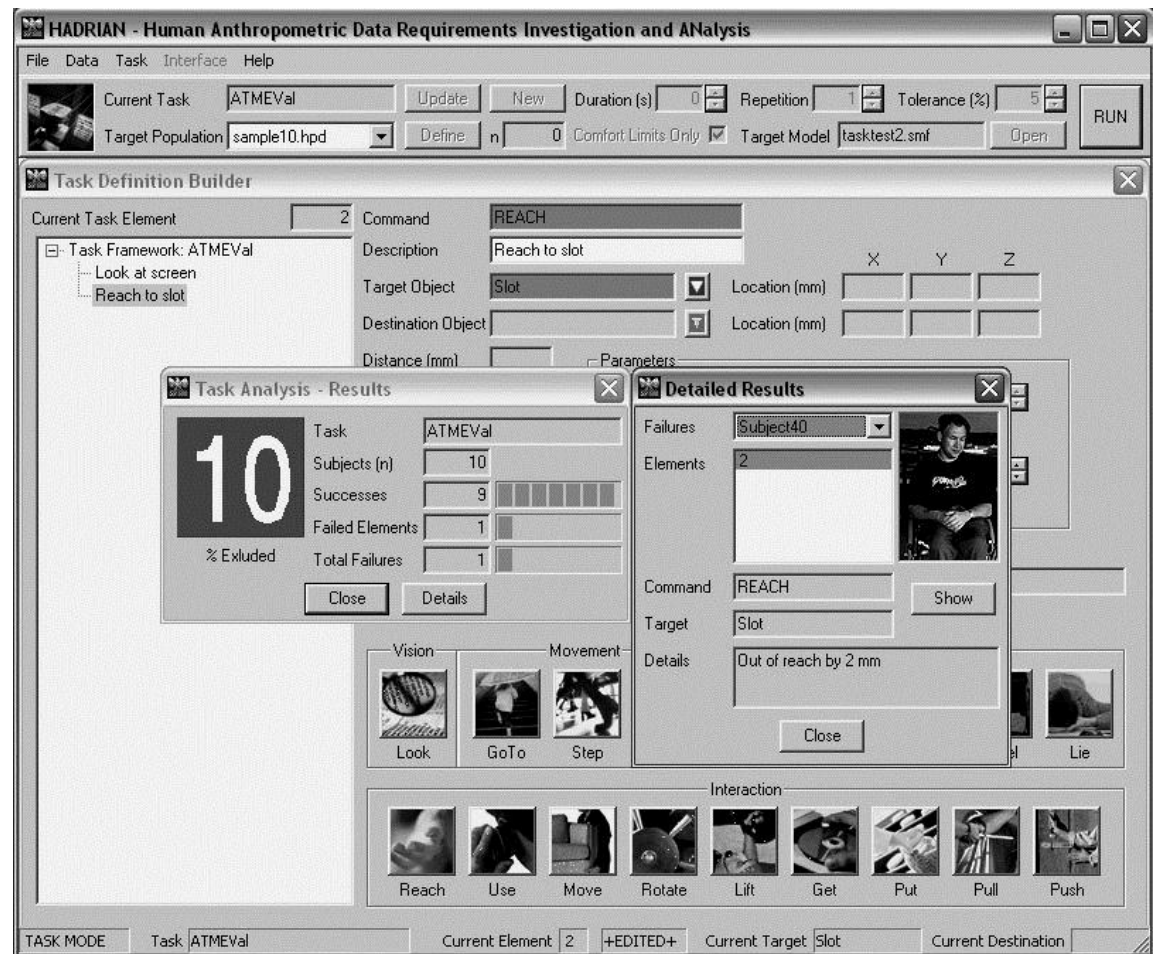

Figure 8. Screen shot of the prototype HADRIAN task analysis system, showing the results from a trial analysis where $10 \%$ of the population have been excluded.

Whilst much of the analysis is deliberately automated and a large number of analyses can be performed without intervention, the system also supports a more interactive approach. A designer can run an analysis and be involved in any decision making processes where the system has to resolve some issue. The flexibility of being able to intervene during an evaluation allows the designer to refine the task analysis during early runs and then run more autonomous analyses when the process is more robust. Alternatively, this facility allows the designer to run through the analysis in a more step-by-step approach to understand the issues faced by a particular user at every stage and actively think about how all aspects of the design impact upon its usability.

\section{HADRIAN meets AUNT-SUE}

Current research has expanded the HADRIAN approach to target the second focus of activity identified with our interviews with older and disabled people, that of transport. In addition it has provided an opportunity to address issues beyond the physical, attempting to integrate the cognitive and emotional issues associated with inclusiveness in transport.

AUNT-SUE (Accessibility and User Needs in Transport for Sustainable Urban Environments) is a consortium of UK academic institutions including London Metropolitan University, University College London and Loughborough University, together with local councils and other public and private bodies such as Camden Council, Hertfordshire Council, and the RNIB. The consortium's aim is to produce methodologies for sustainable policies and practices that will deliver effective socially inclusive design and operation of transport and is funded as part of the EPSRC's SUE programme. 
HADRIAN is being developed, to broaden the content of the database and to increase the functionality of the task analysis to incorporate transport-related data (Marshall et al 2008). The HADRIAN database still contains 100 individuals though the sample has changed slightly to accommodate other potential transport users of interest that would not have been included as part of the first study. For example, people with young children that were pushchair users and thus reported difficulties with using some forms of transport.

The complexity of transport related issues required significant amounts of additional data to be collected as part of the AUNT-SUE study. Additional tasks were added to the earlier kitchen based tasks and included entering and exiting from a range of public transport types. An adjustable experimental rig was constructed that could be used to simulate entering and existing from UK rail, coach and bus vehicles with a representative range of step heights and handle locations (Figure 9). As before participants were recorded traversing the rig at a range of step heights that represented what they were comfortable attempting.

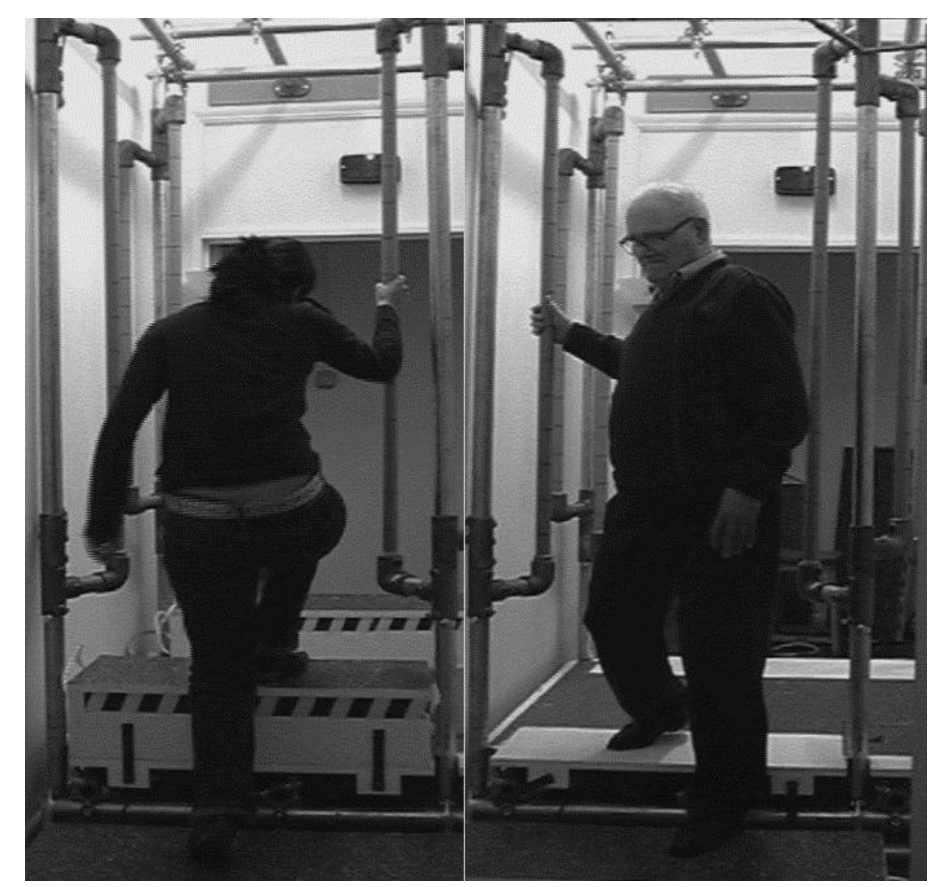

Figure 9. Extracts from video clips of the vehicle ingress / egress rig in use by participants.

To supplement, and potentially replace, traditional anthropometric measures the study has also been collecting whole body scanned data. Using a [TC]2 whole body scanning system, subjects have been scanned to capture their body form (Figure 10). The body scan provides a significant number of advantages including: the extraction of many more body measures than would be practicable using traditional methods, the ability to reprocess the data at a later date if additional measures are required without having to try to recall all the subjects, and a computer representation of the subject's body form which could be used for human modelling purposes in the future. However, the technology is still in development for this kind of application. The ability to record seated pose data is relatively under-developed, extremities such as the top of the head, hands and feet are not complete and so data on these areas must be captured separately. Of particular concern for applications such as HADRIAN is the ability to scan wheelchair users. If the user is capable of transferring to a standard stool then scans are possible. However, if the user must be scanned in their own chair more research needs to be done in order to make this a robust process. 


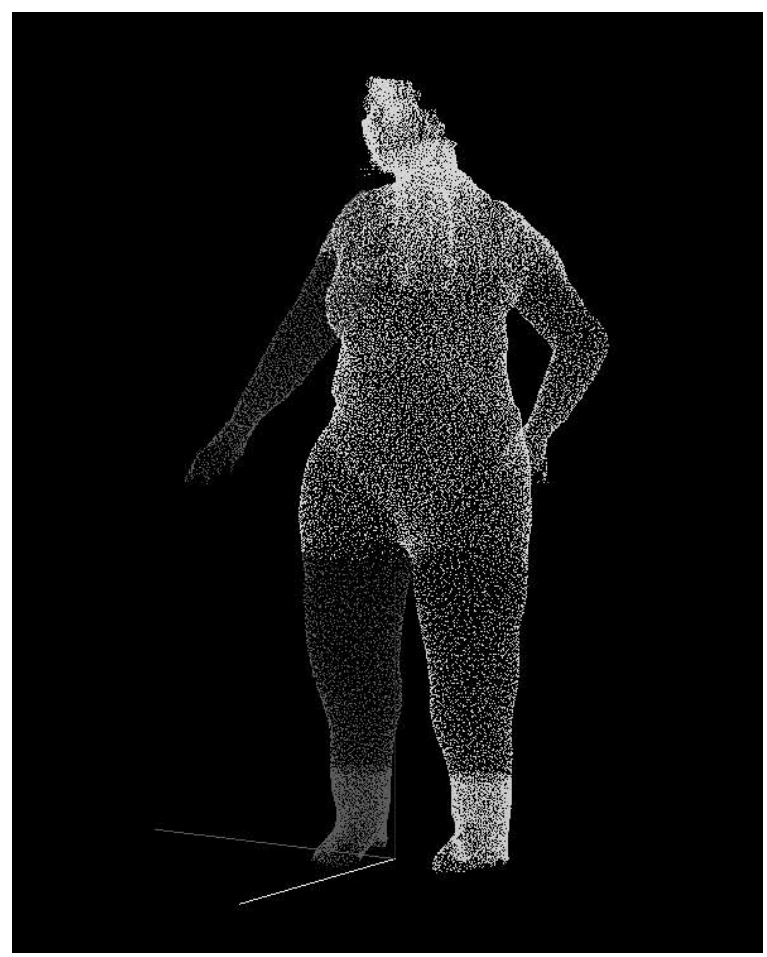

Figure 10. Body scan data from the $[\overline{\mathrm{TC}}] 2$ whole body scanner provides a surface 'mesh' from which surface measures and joint centre data can be extracted.

Whilst the data outlined above enhance the database and improve its applicability to transport they are still only applicable to physical design problems. The initial version of HADRIAN and indeed, most ergonomics design and human modelling tools such as SAMMIE, work within the physical realm. However, as part of the AUNT-SUE project our aim is to expand the database beyond the physical into cognitive, emotional and sensory data associated with travel. These data cover the individual's ability to deal with tasks such as route planning, dealing with crowds and the effects of crowding on the transport design, understanding signs and other public information under conditions of high visual noise, issues with lighting, and the effects of perceptions of crime and personal safety. All of these elements are complex problems to understand and, in particular, to manipulate into a useable data resource. However, they are often some of the most fundamental issues when people are excluded. Thus, if we consider the design of a ticket machine, the machine itself may be highly inclusive, accommodating a broad range of users. However, when the machine is placed in its operating environment it fails to be inclusive due to the dark and secluded location dissuading users from attempting to access it. Alternatively, a perfectly accessible train design may exclude users who cannot reach the train due to poor signage, or timetabling.

Part of our strategy to capture cognitive and emotional data was through the development of a Transport Activities Questionnaire. Participants were asked questions concerning: their physical abilities; any problems encountered when using trains, buses, trams, London-style taxi cabs and minicab taxis; their ability to walk distances, as well as issues surrounding taking luggage on the different transport modes; the types and frequency of journeys made; problems in using stairs, lifts or escalators; and difficulties in understanding timetables and signs. The questionnaire also included a request for information about problems experienced in the local area. Thus the questionnaire provides information concerning issues that may arise at any point during the whole journey process. 


\section{Whole journey inclusiveness}

HADRIAN's development has been targeted at addressing discrete design problems or products. However, the concept of inclusive transport is not solely related to any single piece of design, rather it concerns a network or system of designed elements. These designs could include everything from a flight of steps to a train carriage and yet they all form potential barriers to travel. This network is part of the transport infrastructure, combining a number of directly related, and indirectly related design problems that must be addressed holistically if inclusive transport is taken in the context of the 'journey'.

The journey is part of our perception that inclusive transport is there to enable users to travel from one place to another. To succeed in providing truly inclusive transport we must be able to ensure that our door-todoor journey for example, from home to the doctor, from the bank to the theatre, or from the airport to a relative's house, is possible at every stage. Two tools are being developed to address this need; the Inclusive Journey Planner and the Journey Stress Calculator.

The Inclusive Journey Planner aims to enable end-users of public transport to find the best way to make a particular journey and assess whether or not they will find the journey accessible. The end result will be a prototype internet journey planner along with guidance which may be used to inform the design of future versions of existing journey planners such as that provided by Transport for London (TfL 2008).

Preliminary research was carried out to investigate how current UK journey planners provide travel information and how they might be improved upon. This resulted in the identification of more than 60 individual design recommendations that could be implemented in the Inclusive Journey Planner prototype. The majority of these are encompassed by four main improvement concepts: Personalisation that allows users to customise the interface to provide only the options relevant to them, Genuine Journey Choice that provides real journey alternatives as opposed to the same option merely at different times, Rich Journey Plans that include additional data on features or conditions such as steps, toilets, crowding at that time of travel or service problems, and Better Walking Routes that provide actual navigation information for walking including pedestrian crossings, changes in elevation, cash machines and so on..

The Journey Stress Calculator will be used to assess whole journey accessibility from the perspective of transport professionals wishing to investigate ways to improve transport in a particular geographical area. Taking a journey plan as an input, it will evaluate potential 'stressors' in a journey such as having to climb steps or cross a road, navigating an unfamiliar route, or deal with a heavily crowded area. Each stressor is compared with the ability of each of the 100 HADRIAN individuals in order to model their stress level throughout the journey.

The Journey Stress Calculator will provide results with different levels of detail to allow interrogation of individual stressors, people and journey stages as well as providing overviews of the whole journey and an overall journey stress score. This enables transport professional and practitioners to identify which people are most likely to avoid a journey, compare the accessibility of different routes and ensure spending is targeted at removing stressors that cause greatest exclusion.

\section{Ongoing HADRIAN development}

The database has been updated with all of the additional data collected as part of AUNT-SUE. The next stage is to further develop the prototype with a suitable user interface for designers and other users who wish to explore the data. Our intention is to make the HADRIAN database available as a stand alone resource in addition to being packaged with the analysis tool. In this way we can reach a broader audience than those interested in human modelling, providing a design resource that can inform inclusive design and foster empathy between designers and users. 
It is intended that developments to the task analysis element of the HADRIAN system will also take the whole journey approach to the assessment of all tasks that involve movement from one individual design, or interaction point, to the next. Individual designs will still be the main focus of evaluation but they will be taken in the context of the 'journey' and the designer will be able to evaluate the accessibility of a series of distributed tasks rather than have to consider each element in isolation. This approach should then provide a much more realistic evaluation of the inclusiveness of a design.

In addition to developments in the broader functionality of HADRIAN, the analysis tool is currently being validated and refined for its ability to assess individual designs. Initial validation was carried out at the end of the EQUAL phase of research and highlighted that HADRIAN was capable of predicting comparable levels of design exclusion when compared with the real world (Marshall et al 2004). The validation also identified that the model for predicting the postures adopted during tasks still required more work.

For AUNT-SUE, HADRIAN will go through a second validation. Our philosophy has always been that given the correct experience and expertise in ergonomics and the use of human modelling tools, coupled with appropriate data, a thorough and accurate investigation could be made of any human / product interaction at an early stage in the design process. However, as we have discussed this is unlikely for most designers or design teams. Thus, we have started a series of validation studies that will explore this philosophy The studies are designed to compare the use of human modelling in the form of SAMMIE and HADRIAN firstly, to one another, and secondly to the benchmark set by performing a user trial using a real product and real people.

The studies focus on assessing the inclusiveness of a common product (an ATM provided by our project collaborator NCR (National Cash Registers)). The ATM was chosen as it represents a well used and understood product that is often used during many journeys or other activities. The studies take three basic approaches:

1. A validation assessment of a CAD model of the ATM in SAMMIE by an experienced ergonomist who has worked with older and disabled people on many occasions (Figure 11). The ergonomist is also experienced in using human modelling software and the design of ATMs. 10 people from the HADRIAN database will be used for the assessment (Note: the same 10 people will be used for all three studies in either their real or virtual forms). The positioning of the participants in relation the ATM was considered to be a crucial aspect of the analysis, and the experience of the ergonomist has been heavily relied upon to position the human models appropriately.

2. A validation assessment of a CAD model of the ATM using HADRIAN by a designer with a small amount of training in the HADRIAN system.

3. A benchmark user trial with a physical model of the ATM conducted by an experienced ergonomist. The results from the analysis using real participants will then be compared to the postures adopted and positioning of the participants in the two validation studies.

In each of the first three studies the tasks used for the analysis will be the same. The basic task of "getting cash from the ATM" has been broken down into task elements in the manner outlined earlier. This has resulted in every interaction point on the ATM being a target for a reach and vision analysis i.e. the card slot, PIN pad, screen buttons, statement printer, deposit slot, statement printer, receipt printer and cash collection locations. Other issues such as mounting height of the ATM have been factored in based on data for global mounting height range information provided by NCR. 

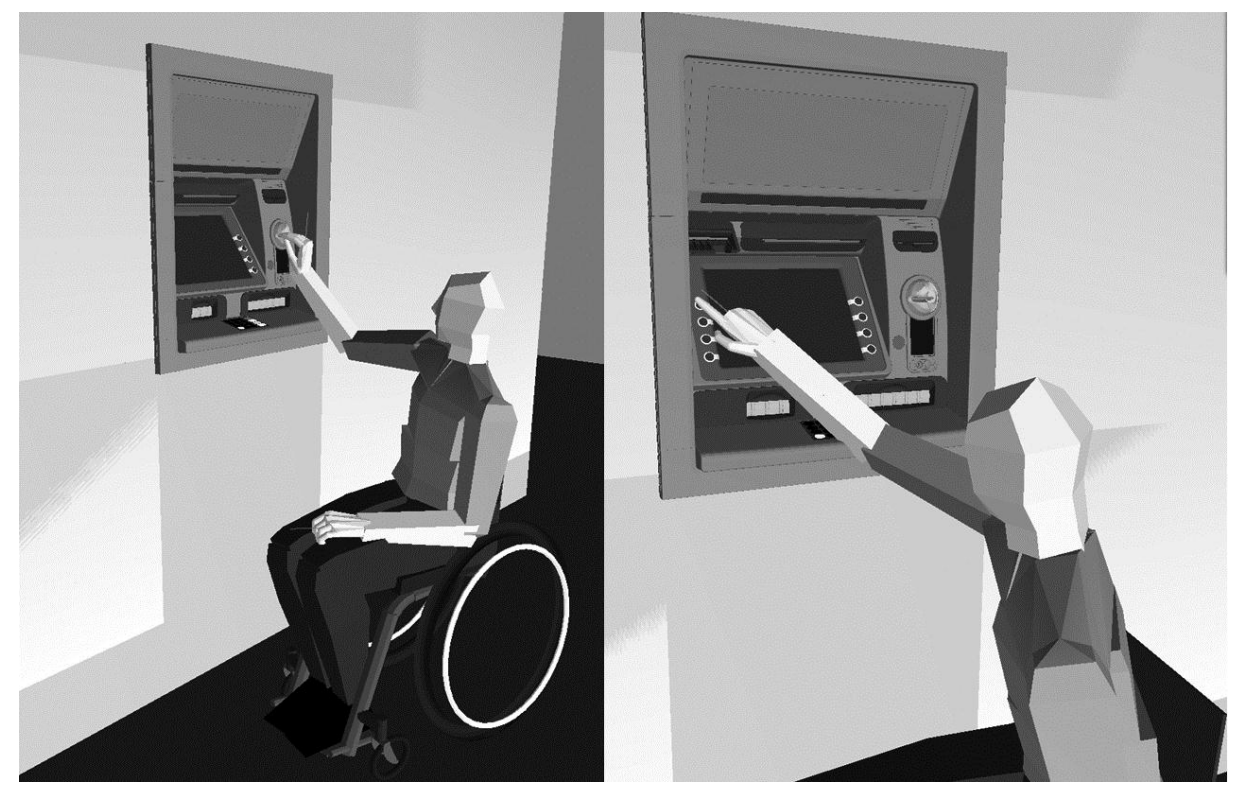

Figure 11. Validation of an ATM being performed in the SAMMIE system with HADRIAN data.

The sample of participants has been selected to cover a number of issues that pose a challenge for both forms of virtual analysis and to provide a basis for potentially interesting results. Thus the sample includes people with a range of age, size and ability that covers a broad range of the population. In total 10 people have been identified including three wheelchair users, one of who had good upper body strength and upper body mobility, one whom had a broken back, a weakened left arm, and arthritis which limited the joint mobility, and one with multiple sclerosis. The remaining subjects all suffer from different types of arthritis. Arthritis is the leading cause of chronic disability amongst older people (Sarzi-Puttini P et al 2005) and thus is a particularly relevant condition to explore during the validation. The validation of the ability to model this limited joint mobility in HADRIAN by testing how the predictions the system makes match reality is vital, and is seen as an opportunity to refine the HADRIAN automation process.

After the first three studies have been completed and the results used to refine HADRIAN the fourth study will address a more directly transport related design. The focus of study four is the Docklands Light Railway (DLR) station in Greenwich, London. Studying a whole station will allow assessment of the ability of HADRIAN to address journey related issues. HADRIAN will be used to analyse various interaction points at the station including: ticket machines, lifts, travel card scanners and steps and stairs. Each will be assessed for their inclusiveness and design changes and recommendations will be generated for the subsequent refurbishment of the Greenwich station.

\section{Conclusions}

HADRIAN was been developed to support designers and design teams in adopting a design for all philosophy and in developing inclusive products. Our approach has been to target limitations with current data on people and provide a means to utilise the data to perform virtual ergonomics analyses early on in the design process when real user trials would be prohibitive.

The HADRIAN database provides extensive data on 100 individuals including their size, shape, ability, behaviour, and a range of other information on their background and specific transport related experiences. This database represents a significant step in addressing the identified concerns with data to support design for all activities: 
- Structuring the data around individuals significantly simplifies their application to human modelling including removing concerns with non proportionality of humans, multivariate accommodation, and finding data for all relevant dimensions.

- Presenting the data in a highly visual manner, including photographs and video clips of the individual, encourages empathy with the people being designed for, something not supported by numerical tables found in other currently available sources.

- The combination of physical measures with cognitive and emotional data on travel addresses the need to assess inclusiveness in a holistic manner and not just focus on physical access.

- The sample covers from $<1^{\text {st }}$ to $>99^{\text {th }}$ percentile for the majority of anthropometric measures, and from 1 to 9 on the OPCS severity scales (representing no or very minor impairments through to major impairments in a number of areas).

- The task related data provide application specific and generically applicable data on people's capabilities, together with insights into coping strategies for those with limited mobility, that are highly relevant for design applications even without the use of the task analysis tool.

- The variety of data collected, whilst not exhaustive or representative of the whole population, provides a rich and varied set of data on people, particularly those who are older and disabled that would be very difficult and time consuming to replicate for individuals or team looking to gather data on target users.

- It is believed that taken in the context of a real user trial, the cost, time, and sheer complexity of putting together a user trial with a similar sample, would be prohibitive and so the HADRIAN database provides an invaluable resource for those working on design for all projects.

- It is acknowledged that the addition of data is not trivial and that further work is needed to understand all the issues and to look at how that can be facilitated.

The data can be employed through a simple task analysis system to assess the inclusiveness of a design. This automated predictive process addresses the concerns identified with the use of data in design for all activities:

- Taking a task analysis approach and focusing on driving the system with as few a demands on the user, reduces the complexity of driving a human modelling system and the expertise required to perform an accurate evaluation.

- By focusing on the needs of designers and ergonomists attempting to design for all, the task analysis system makes human modelling more accessible.

- The limited level of detail required supports the application of the task analysis system early on in the design process providing feedback on potential issues for users that would be difficult to obtain in any other way.

- The speed of analysis and the ability to evaluate 'what if' scenarios with limited cost, supports iterative use and refinement of ideas towards an inclusive solution.

Whilst HADRIAN addresses discrete design problems, transport research also highlights the need to address system level problems through the concept of a whole journey. Individual travellers will not focus on individual elements of a journey but rather be concerned with their ability to get from A to B. Therefore development has begun on an Inclusive Journey Planner and a Journey Stress Calculator addressing the needs of the end user, someone wishing to make a journey fully informed of their travel options, and that of the designer or planner wishing to understand the inclusivity of some element of transport infrastructure before costs are committed and changes implemented. 
The advantages of the approach taken by this research and presented in this paper have been outlined here. However, there are a number of areas that are more speculative or require further refinement, enhancement, or may require a different approach. To address this, HADRIAN is currently undergoing a series of validation studies to assess its efficacy: firstly a comparison with an experienced ergonomist using a human modelling system to perform a virtual assessment, and secondly a comparison with the same assessment but with real people and a physical model. The results will give a clear indication of the strengths and weaknesses of both the data and the task analysis components of the tool and will be sued to refine the system and suggest areas for further work. After validation a dissemination route is planned that includes an accessible on-line resource for the data together with a phased introduction of the task analysis tool to designers to support their efforts and help establish inclusive design as an integrated part of design practice.

\section{Acknowledgements}

The authors gratefully acknowledge the financial support of the Engineering and Physical Sciences Research Council (EPSRC) through the Extending Quality of Life initiative (EQUAL) and subsequently through the Sustainable Urban Environments Programme (SUE). We would also like to thank the 'individuals' who gave up their time to support this research.

\section{References}

Adultdata., 1998. The handbook of adult anthropometry and strength measurements - data for design safety. L. Peebles and B. Norris, eds. Department of Trade and Industry.

Azmin-Fouladi, N. and Evans, G., 2007. Designing the Inclusive Journey Environment, Proceedings of INCLUDE 2007, Royal College of Art, London, 2007.

CAESAR., 2008. Civilian American and European Surface Anthropometry Resource [online]. Available from: http://store.sae.org/caesar/ [Accessed 06/08/2008].

Coleman, R., Lebbon, C., Clarkson, J. and Keates S., 2003. From Margins to Mainstream, In: J. Clarkson et al eds, Inclusive Design, design for the whole population, London: Springer-Verlag, pp 1-25.

Das, B. and Kozey, J., 1999. Structural anthropometric measurements for wheelchair mobile adults. Applied Ergonomics 30 (5), 385-390.

DDA., 2005. Disability Discrimination Act 2005 [online]. Office of Public Sector Information. Available from: http://www.opsi.gov.uk/acts/acts2005/ukpga_20050013_en_1 [Accessed 06/08/2008].

Goodman, J., Dong, H., Langdon, P.M. and Clarkson, P.J., 2006. Industry's response to inclusive design: a survey of current awareness and perceptions. In: P.D. Bust ed. Contemporary Ergonomics 2006, proceedings of the Annual Conference of the Ergonomics Society. Cambridge, UK, April 2006, pp. 368-372.

Goswami, A., Ganguli, S. and Chatterjee, B., 1987. Anthropometric characteristics of disabled and normal Indian men. Ergonomics 30 (5), 817-823.

Gyi, D.E., Porter, J.M. and Case, K., 2000. Design practice and 'designing for all', Proceedings of the IEA 2000/HFES 2000 Congress, Human Factors and Ergonomics Society, San Diego, California, USA, August 2000.

Gyi, D.E., Sims, R.E., Porter, J.M., Marshall, R. and Case, K., 2004. Representing older and disabled people in virtual user trials: data collection methods", Applied Ergonomics, 35 (5), 443-451.

Hasdogen, G., 1995. The Nature and Limitations of User Models in the Household Product Design Process. Design Studies, Vol. 17 (1), 19-33.

Hobson, D. and Molenbroek, J., 1990. Anthropometry and design for the disabled: experiences with seating design for the cerebral palsy population. Applied Ergonomics 21 (1), 43-54. 
Keates, S. and Clarkson, P.J., 2003. Countering Design Exclusion: an introduction to inclusive design. London: Springer-Verlag.

Marshall, R., Summerskill, S.J., Porter, J.M., Case, K., Sims, R.E., Gyi, D.E. and Davis, P.M., 2008. Multivariate design inclusion using HADRIAN, Proceedings of the SAE 2008 Digital Human Modelling for Design and Engineering Conference and Exhibition, SAE Paper No 2008-01-1899, Pittsburgh, USA, June 2008, pp 1-8.

Marshall, R., Case, K., Porter, J.M., Sims, R.E. and Gyi, D.E., 2004. Using HADRIAN for Eliciting Virtual User Feedback in 'Design for All', Journal of Engineering Manufacture; Proceedings of the Institution of Mechanical Engineers, Part B, 218(9), 1st September 2004, 1203-1210.

Marshall, R., Case, K., Oliver, R.E., Gyi, D.E. and Porter, J.M., 2002. A task based 'design for all' support tool", Robotics and Computer-Integrated Manufacturing, 18(3-4), 1st June 2002, 297-303.

Martin, J., Meltzer, H. and Elliot, D., 1994. OPCS surveys of disability in Great Britain: The prevalence of disability among adults, London: HMSO.

Morrissey, M., 2004. The SAFEWORK human simulation tool. In: N.J. Delleman, C.M. Haslegrave, and D.B. Chaffin eds. Working Postures and Movements - tools for evaluation and engineering. Boca Raton: CRC Press LLC, 437-444.

Oliver, R.E., Gyi, D.E., Porter, J.M., Marshall, R. and Case, K., 2001. A Survey of the Design Needs of Older and Disabled People, In: M.A. Hanson ed. Contemporary Ergonomics 2001 proceedings of the Annual Conference of the Ergonomics Society., Cirencester: Taylor \& Francis, 2001, pp 365-370,

Paquet, V. and Feathers, D., 2004. An anthropometric study of manual and powered wheelchair users, International Journal of Industrial Ergonomics, 33 (3), 191-204.

PeopleSize., 1998. Reference visual anthropometry software [online]. Open Ergonomics. Available from: http://www.openerg.com/psz/index.html [Accessed 06/08/2008].

Pheasant, S.T., 1996. Bodyspace: Anthropometry, Ergonomics and the Design of Work, 2nd ed. London: Taylor \& Francis.

Porter, J.M., Case, K., Marshall, R., Gyi, D.E. and Sims, R.E., 2004. Beyond Jack and Jill: designing for individuals using HADRIAN, International Journal of Industrial Ergonomics, 333,1st March 2004, 249-264.

Porter, J.M., Marshall, R., Freer, M. and Case, K., 2004. SAMMIE: a computer aided ergonomics design tool. In: N.J. Delleman, C.M. Haslegrave, and D.B. Chaffin eds. Working Postures and Movements tools for evaluation and engineering. Boca Raton: CRC Press LLC, 454-462.

Porter, C. S. and Porter, J. M., 1999. Designing for usability: input of ergonomics information at an appropriate point, and appropriate form, in the design process. In: W. Green and P. Jordan, eds. Human Factors in Product Design, London: Taylor \& Francis Ltd, 15-25.

Raschke, U., 2004. The Jack human simulation tool. In: N.J. Delleman, C.M. Haslegrave, and D.B. Chaffin eds. Working Postures and Movements - tools for evaluation and engineering. Boca Raton: CRC Press LLC, 431-437.

Roebuck, J.A. Jnr., Kroemer, K.H.E. and Thomson, W.G., 1975, Engineering anthropometry methods. New York: John Wiley.

Robinette, K.M., Daanen, H., Paquet, E., 1999. The CAESAR project: a 3-D surface anthropometry survey. Proceedings of the second International Conference on 3-D Digital Imaging and Modeling. Ottawa, Canada, October 1999, pp. 380-386.

SAMMIE CAD., 2008. SAMMIE CAD Ltd [online]. Available from: http://www.sammiecad.com [Accessed 06/08/2008]. 
Sarzi-Puttini, P., Cimmino, M.A., Scarpa, R., Caporali, R., Parazzini, F., Zaninelli, A., Atzeni, F., Canesi, B., 2005. Osteoarthritis: an overview of the disease and its treatment strategies. Seminars in arthritis and rheumatism, 35 (1), 1:10.

Seidl, A., 2004. The RAMSIS and ANTRHOPOS human simulation tools. In: N.J. Delleman, C.M. Haslegrave, and D.B. Chaffin eds. Working Postures and Movements - tools for evaluation and engineering. Boca Raton: CRC Press LLC, 445-453.

SizeUK., 2008. UK national sizing survey [online]. Available from: http://www.sizeuk.org [Accessed 06/08/2008].

TfL 2008. Journey Planner [online]. Transport for London. Available from: http://www.journeyplanner.org [Accessed 06/08/2008].

Treleaven, P., 2007. How to fit into your clothes: Busts, waists, hips and the UK National Sizing Survey. Significance, 4 (3), 113-117.

\section{List of figures}

Figure 1. The human modelling system SAMMIE being used in the evaluation of a train cab design for the Rail Safety and Standards Board (RSSB).

Figure 2. Screen shot of the prototype HADRIAN database - showing anthropometric data for an individual.

Figure 3. Individuals performed a variety of kitchen based tasks from which capability and behaviour were recorded.

Figure 4. Screen shot of the prototype HADRIAN task analysis system, showing the building of a task definition.

Figure 5. Orientation differences for a wheelchair user during a task analysis within HADRIAN.

Figure 6. Postures adopted within a task analysis influenced by the behavioural coding recorded for individuals in the database.

Figure 7. Screen shots of SAMMIE performing a HADRIAN task analysis. Top left shows a simple ATM model. Top middle

shows a tall individual in the database successfully performing a reach task to the card slot. Top right shows a wheelchair user from

the database failing to reach the card slot. Bottom left shows the same ATM model with a quick change of dropping the whole

ATM by $100 \mathrm{~mm}$. Bottom middle shows the tall individual still able to reach the card slot. Bottom right shows the wheelchair user is now capable of reaching the card slot.

Figure 8. Screen shot of the prototype HADRIAN task analysis system, showing the results from a trial analysis where $10 \%$ of the population have been excluded.

Figure 9. Extracts from video clips of the vehicle ingress / egress rig in use by participants.

Figure 10. Body scan data from the $[\mathrm{TC}] 2$ whole body scanner provides a surface 'mesh' from which surface measures and joint centre data can be extracted.

Figure 11. Validation of an ATM being performed in the SAMMIE system with HADRIAN data. 